\title{
CONCEPT MAPS COLLABORATIVE CREATION IN PRODUCT LIFECYCLE MANAGEMENT
}

\author{
Oliveira, Daniela (1); \\ Gardoni, Mickael (1); \\ Dalkir, Kimiz (2) \\ 1: École de Technologie Supérieure, Montreal, Quebec; \\ 2: School of Information Studies, McGill University, Montreal, Quebec
}

\begin{abstract}
One of the greatest challenges of effectively managing knowledge in an organization is promoting seamless connections of operations between departments, the Product Lifecycle Management paradigm. It is also a paradigm that fosters organizational adaptability and quick change in production. Historically, information systems supporting operations have been developed with a specific department's culture in background. Due to this legacy, connecting data, information systems and people across the product lifecycle is an ongoing puzzle for organizations. Theorists and practicians agree on the need to include employees' expertise and vision in this process. However, this involves multiple perspectives and needs that are different but equally valid make. This study explores a tacit knowledge capture tool to be used as a means to voice the interaction and negotiation among employees. Through its influence on ontologies, concept maps collaborative creation can provide a usability tool focused on meaning throughout the product lifecycle. A literature review of the challenges involved and of the proposed tool is presented, followed by a use case and concluded with recommendations drawn from theory and practice.
\end{abstract}

Keywords: Product Lifecycle Management (PLM), Conceptual design, Ontologies, Knowledge management, Group consensus

\section{Contact:}

Oliveira, Daniela

École de Technologie Supérieure, Montreal, Quebec

Génie de la production automatisée

Canada

daniela.innovation.oliveira@gmail.com

Cite this article: Oliveira, D., Gardoni, M., Dalkir, K. (2021) 'Concept Maps Collaborative Creation in Product Lifecycle Management', in Proceedings of the International Conference on Engineering Design (ICED21), Gothenburg, Sweden, 16-20 August 2021. DOI:10.1017/pds.2021.72 


\section{INTRODUCTION}

Knowledge comes in many shapes and sizes. Its diversity turns its transfer into a difficult task. Without effective ways of knowledge transfer, the development of technology to support knowledgeintensive tasks is compromised.

The most widely spread theoretical model of knowledge, the SECI model, divides knowledge into explicit and tacit (Nonaka and Takeuchi, 1995). The division is theoretical and functional. Theoretical, because while knowledge in two dimensions, both of them still refer to the same knowledge. Functional, because an observable criterion is used to divide knowledge into two dimensions. The division allowed research to focus on one or the other dimension, to identify a set of characteristics of each one of the dimensions and to suggest ways of developing, diffusing, nurturing and overall managing that dimension of knowledge.

The observable criterion in question is the expression in some kind of language, a phenomenon named exteriorization. All knowledge expressed in documents, further referred to as codified knowledge, was first made explicit. Explicit knowledge finds its origins in tacit knowledge (Nonaka and Takeuchi, 1995). Tacit knowledge refers to knowledge before exteriorization. It resides inside an individual's mind. The SECI model implies four hypothetical and different sources of knowledge: two individuals and two documents:

- The knowledge flow from an individual to a document, as mentioned above, is named exteriorization;

- The knowledge flow from a document to an individual is named interiorization;

- The knowledge flow between documents is named combination;

- The knowledge flow between individuals is named socialization (Nonaka and Takeuchi, 1995).

The model predicts that individuals are capable of transferring and absorbing knowledge without its translation into some kind of language. Observation and imitation are processes that facilitate socialization (Nonaka and Takeuchi, 1995).

The use of verbal language in the diffusion of documents has been central to allowing rapid diffusion of knowledge (Nelson et al., 2002). However, the exteriorization flow requires the creation of a mental model, a way to model knowledge, which involves the reduction of the knowledge in question (Cowan and Foray, 1997).

To absorb knowledge from a document, an individual must employ their pre-existing meaning structures. These are structures based on the knowledge the individual holds before the absorption process (Dixon, 1999). They are also used to combine documents or to absorb tacit knowledge. Meaning structures are part of tacit knowledge, derived from tacit knowledge and created from tacit knowledge. As a consequence, as much as the tacit knowledge previously held by an individual determines their capacity to absorb new knowledge, the new knowledge will influence further knowledge acquisition by the individual. The subsequent movement of employing and creating meaning structures is represented in the SECI model by a spiral covering both sources of knowledge, the other individual and the document, as well as the combination of documents. The spiral also represents knowledge development through subsequent cycles of knowledge flows.

The model was extended with the inclusion of the $b a$ concept. Ba can be roughly translated to "place" or "context". The concept conveys the idea that meaning structures can be common to many individuals and be recognized as such by those individuals. Knowledge needs $b a$ to be transferred. It can, however, be separated from $b a$, becoming information (Nonaka and Konno, 1998). The introduction of the $b a$ concept highlights the differences between information consumption and knowledge absorption. Knowledge absorption requires the sharing of mental models to some extent. These mental models provide the user with the feeling of belonging to a collectivity, of intuitivity.

The extended model implies three consequences: first, information is different from explicit knowledge. Second, information can be interpreted without the understanding of its context of origin. It will not, however, cover the original knowledge extent. As argued by Stoyanova and Kommers (2002), while information can be transmitted using only verbal structures, knowledge "needs to be constructed as a web of meaningful connections" (p.112). Second, context is external to knowledge expression. Therefore, explicit knowledge and information share the same and only criterion used to differentiate explicit from tacit knowledge: the expression in some kind of language. 
Verbal language implies a reduction in the transferred knowledge and can be detrimental to creativity (Cowan and Foray, 1997). As an alternative, other methods are used in design thinking to facilitate the production of original and innovative ideas (Rambo et al., 2007).

Although few studies on design research discuss knowledge composition or approach, the quest for effective knowledge flows in the design process is undeniable. Effective design aims to replicate users' mental models and create an intuitive sensation, in contrast to producing artifacts that convey the creator's own mental models. Design processes should, therefore, promote knowledge transfer from potential user to designer, in contrast to information transfer, where the mental models employed are the ones held by the creator and not by the potential user. Efforts to achieve the transfer of ba, context, meaning structures, mental models can be observed in data collection techniques. Context inquiry, for instance, foster the transfer of tacit knowledge through observation and through exteriorization and combination of meaning structures in the forms of questions aiming to validate designer's understanding (Babish, 2019). Data visualization through personas offer an opportunity for the designer to put themselves in the user's shoes and better navigate their mental models while designing artifacts for their use (Nielsen, 2019).

Similar efforts support effective design of artifacts that foster knowledge application. Artifacts that foster knowledge application help users act on reality based on the knowledge they hold. Artifacts for knowledge-intensive environments, however, carry additional challenges:

- Knowledge-intensive environments might present the need to represent the knowledge of employees. In that sense, the designer must not only understand the mental model of the user, but also how the user would convey that mental model to their peers. In other words, it is a question of not only understanding how knowledge is organized by the user, but also how the user would organize that knowledge;

- Knowledge in knowledge-intensive environments might be distributed in different departments, with very different user profiles;

- Knowledge-intensive environments might present a complex interplay between data, information and different kinds of knowledge.

This study focuses on the creation of interfaces presenting different data, information and knowledge sources and the connections between them in order to foster knowledge representation in knowledgeintensive environments.

\section{KNOWLEDGE MANAGEMENT AND PRODUCT LIFECYCLE MANAGEMENT}

The challenge in implementing Product Lifecycle Management lies in the fact that functions pertaining to the design, development, commercialization and support of a product have been traditionally carried out by different, specialized departments in the organization (Kale, 2016). In most cases, departmental subcultures have been developed, demanding the integration of different thoughts paradigms and often, specific vocabularies (Oliveira, Gardoni, \& Dalkir, 2018). These subcultures are the natural expression of the development of collective tacit knowledge. Lack of understanding of the value and nature of tacit knowledge in early stages of the product lifecycle management literature led to the attribution of the challenges surrounding tacit knowledge to organizational problems (Batenburg, Helms, \& Versendaal, 2006), although they are now fully recognized as a gap in product lifecycle management (Kärkkäinen, Pels, \& Silventoinen, 2012).

More often than not, tacit knowledge is difficult to articulate, although the level of the challenge depends on the person that holds that knowledge: what is difficult to articulate for someone might not be for another (Dalkir, 2017). Tools and techniques to capture tacit knowledge help managers navigate the organizational tension among processes, or the way things are formally organized, and the practice, the way things are really done (Brown \& Duguid, 2000). The inclusion of tacit knowledge in processes improvement projects has a positive impact in those projects (Anand, Ward, \& Tatikonda, 2010).

The inclusion of tacit knowledge may lead to:

- The adoption of the best information and data sources;

- Real-life needed steps in a process;

- The representation of the key players for the operationalization of a task. 


\section{CONCEPT MAPS AND TACIT KNOWLEDGE CAPTURE}

Tacit knowledge can be seen as the perspective of the world held by an individual, the ways in which they go about accomplishing their tasks, their ability to engage with other individual's projects and their skills and experience, among other elements. Professionals of the same domain, people of the same age group or the same culture or any other group of individuals may have the same tacit knowledge in common. The knower is not always aware that they hold this knowledge, which adds to the challenge of mapping tacit knowledge in an organization. In addition, tacit knowledge may be very difficult to articulate.

Tools supporting the identification and articulation of tacit knowledge are very helpful to integrate this kind of knowledge in any initiative. Concept maps are among those tools. Their way of representing knowledge, somewhere between drawings and language, as explained by Umoquit et al. (2013), considering the studies produced by Banks (2001), makes of them a great candidate to retain some of the multifaceted nature of tacit knowledge.

In the educational environment, concept maps have helped students of different levels and disciplines. They have also helped researchers to understand research data (Umoquit, Tso, Burchett, \& Dobrow, 2011). Concept maps help the expression of the connection between an individual's behaviour (their actions) and their tacit knowledge (their skills).

\section{CAPTURING TACIT KNOWLEDGE WITH A CONCEPT MAP: AN EXPERIENCE}

An exercise to explore the potential of concept maps was done with a subject matter expert from the staff of an organization charged with the construction and maintenance of road infrastructure. The organization is currently considering product lifecycle management. The aim of the exercise was to identify the necessary concepts to foster the transition from management focused on projects to management focused on the product lifecycle. The exercise's scope was centred in the creation of the product.

The implementation of project-based management happened in 2012 in this organization. It was joined and supported by the creation of a document classification system, implemented in 2016. The classification system offers ways to group documents of a project since the first steps of product design and covers the product lifecycle up to its transfer to the maintenance team. The organization also employs a classification plan that covers all organizational activities, updated in 2018. Document management is supported by a technological solution where both classification systems were implemented.

The project management methodology and its classification system follow five steps: Opportunity Study, Design, Plans and Specifications Preparation, Construction and Evaluation. As mentioned before, one classification system supports the steps from Design to Evaluation, while the overall classification plan covers all organizational activities, including those taking place before or during the Opportunity Study phase.

The participant had been in charge of the Opportunity Study team for a couple of years. The organizational management of projects ensures that all projects have a project number assigned to them at the end of the Opportunity Study phase. The project number is widely used across different activities throughout the organization and an essential piece of data in a number of databases supporting information systems, either as a primary or external key. In other words, in the human activity dimension, the project number identifies a project both in the departments that are directly involved with the management of the project and in the departments whose activities are more loosely related to project management. Parallelly, in the information systems dimension, the project number's use is also twofold: as a primary key, a main code of reference, in information systems closely related to project development, such as the one holding project deadlines, budget and names of professionals responsible for the project, and as an external key, a liaison code to projects in information systems that are loosely related to project development, such as the one holding information on supplier payments.

To idealize new products, the Opportunity Study team has to regroup needs expressed by product users and by partner organizations representing those users. Some of these partner organizations manage the territory where products are implemented. The communication with users and partner organizations is assured by other teams. The project management methodology does not apply to the 
communications initiated by users or by partner organizations. The document management supporting communications follows the classification plan of the organization. In their communication with the organization, partner organizations may refer to products by their commonly known name ("main street", in the case of a municipality, for example) or just generally express concerns. Although these concerns may be generalized to all products managed by the organization, partner organizations voice the best interest of users in their territory, which cover only a portion of the organization's products. The extent of that portion needs not to be explicitly mentioned in the communication with the organization.

Documents produced by the departments responsible for communication with users and partner organizations are grouped in chronological order according to the department responsible for their creation. The creator department can also employ a code inserted in the document title to help retrieval through the technological solution used to hold all documents produced by the organization. The code depends on the creator department's context: complaint number, request number and so on. Although this system possibly satisfies the creator departments' needs, it is far from practical for the participant's team. To identify communications regarding a portion of a product, the participant's team has to browse all years and, in each year, browse all partner organizations that manage the territory where that portion lies (and all other organizations represented in the classification plan that could possibly have an interest in the product portion), in addition to consulting each communication piece.

In addition, the participant expressed difficulty in grouping the investigation's outcome of their own team using the classification plan. Documents supporting the analysis work performed by their team can be spread across five different classification entries. The browsing or searching effort to identify relevant documents is laborious and cumbersome.

Concept maps were explained to the participant. Next, a concept map with concepts used in the current document management strategy for documents produced in the context of a project (Figure 1) was presented to the participant. The participant recognized the representation of all concepts used in the document management strategy considering documents produced during a project in this concept map. These concepts represented codes, steps in a process, document creators and outcomes. Each one of these elements was represented the same way, by a term inside an elliptical form. The connections between elements serve to illustrate a variety of different relationships.

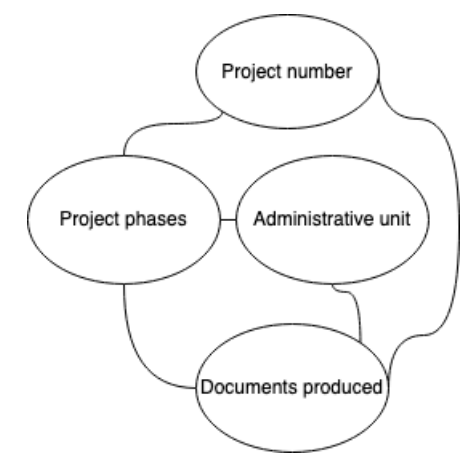

Figure 1 - Concepts used in the current project management practice

A critical thinking activity based on the grouping of documents produced by other teams followed. In this activity, four additional concepts were added to the diagram, "user", "partner", "request" and "complaint".

A subsequent critical thinking activity explored the connection between the four new concepts and the existing ones. The participant identified a piece of information known to most departments of the organization that can be a common code among the departments involved. The use of this code could address the challenge of the grouping of documents their team required. During the critical thinking activities, the representation of a complex reality using minimalist elements provided a rich way for articulating the challenges surrounding the pre-project and the project phase and helped to explore possible elements of a solution. The concept map fostered a broad vision of the issues involved. In addition, the concept map became a way of conveying the solution found.

This exercise illustrates how specialized employees' perception of how things actually work in the organization can be used in favour of departmental integration through the use of concept maps. If members of other departments also took part in the exercise, the concept "geographical reference" could be broken down until a common code or a common combination of codes was found, fostering 
also the integration of the information systems involved. More importantly, because a conceptual connection between different departments and different information systems was found, the concept map became useful to potential PLM efforts. The final concept map follows (Figure 2).

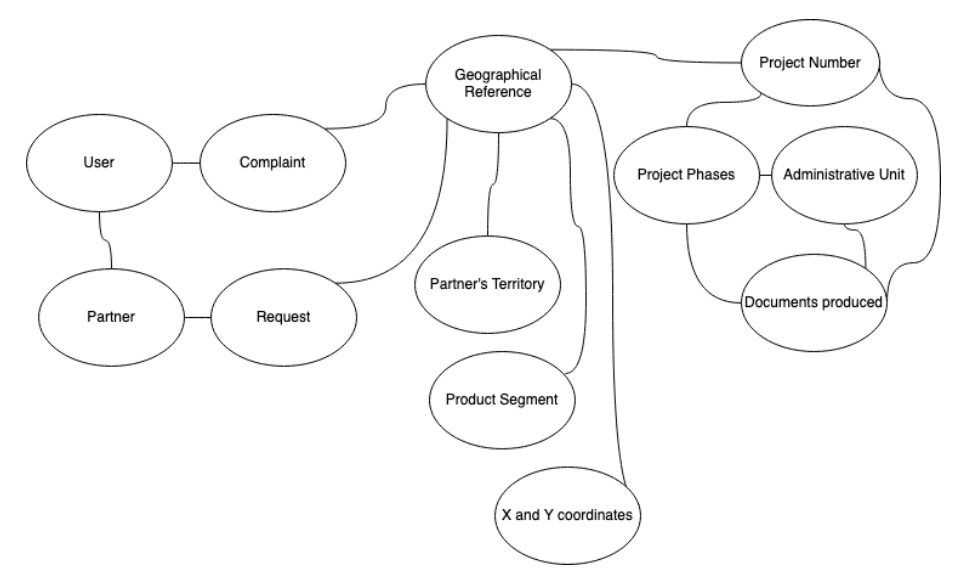

Figure 2 - Proposed connection link of documents and information in pre-project and project

The concept map creation exercise helped the participant navigate data and information from other teams using their own mental model, creating a connexion between their informational environment and the one from other teams. The exercise of expressing the connexions between concepts gave the potential user the opportunity to exteriorize a lot of the tacit knowledge involving work with those concepts, providing a rich opportunity of mental model transfer.

\section{TACIT KNOWLEDGE CAPTURE IN THE PRODUCT LIFECYCLE MANAGEMENT CONTEXT}

Ontologies serve as machine-readable means of representing the context surrounding the knowledge that is represented in specialised systems in product lifecycle management. They help implement connections and represent interdependencies among departments (Smirnov \& Shilov, 2018). An ontology aims to represent the perception of concepts and their relationships as per an individual or of a group of people (Gruber, 1993). Their potential to represent context have made them essential in the integration of management systems (Lanzenberger et al., 2008; Pellini \& Jones, 2011; Pincher, 2010). Their potential on to represent context in specialized systems, as those used in product lifecycle management, is also recognized (Kadiri \& Kiritsis, 2015). The representation of knowledge that ontologies carry aid the management of data pockets holding semantic heterogeneity. Semantic heterogeneity refers to data pockets that may be perceived in different ways by different departments and treated and used in different ways, even though they may have similar labelling or seem to belong to a similar data model (Kadiri \& Kiritsis, 2015; Kermanshahani, 2009; Sheth, 1999; Sheth \& Kashyap, 1993).

Ontologies are commonly developed through the analysis of organizational documents such as policies and procedures, as documented by Joseph and Lourdusamy (2018) or Lim, Liu and Lee (2011). The inherent logic behind the management and use of data or, in other words, the context of data modelling, is extracted from those documents.

Ontologies being developed mostly by information technology experts, their mental model is used in the creation of those ontologies. Consequently, most ontologies do not portrait the mental model of the intended users of the systems where those ontologies are implemented, causing a disconnection with the organizational reality and having the understandable potential to lead to user resistance and frustration (Wognum \& Kerssens-van Drongelen, 2000; Wognum \& Kerssens-Van Drongelen, 2005). A first usability challenge is generated by this process, even more because the environment where these ontologies are deployed is often a knowledge-intensive one, where, as discussed in the Introduction, some of the tasks involve knowledge representation in a system for subsequent use. The second usability challenge lies in the kind of source used for ontology development: explicit knowledge. Arduin et al. (2018) argue that the knowledge residing in an organization cannot be reduced to what has been codified. When performing their work, employees navigate a complex 
environment of explicit and tacit knowledge, tacit knowledge being the kind of knowledge that informs action. The very kind of knowledge that is overlooked by current processes of ontology creation.

Ontology creation begins with its graphical portion (Brilhante, Macedo, \& Macedo, 2006; Castro et al., 2006; Starr \& Oliveira, 2013; Yao \& Gu, 2013). The graphical portion of ontologies is often referred to as conceptual maps (Garshol, 2004; Sowa, 1992). "Concept map" is a term that has been extensively used in education literature to refer to "an effective and efficient way to represent knowledge" (Lambiotte et al., 1989, p. 331), a visual representation of abstract ideas (Novak and Cañas, 2009). While the graphical portion of ontologies respect the content-focused definition of graphical tools for organizing and representing knowledge (Novak and Cañas, 2009) and the visuallyfocused definition of a structural representation made of nodes and labelled lines, each node representing a concept and each one of the lines connecting nodes, a relationship between the concepts it connects (Ruiz-Primo and Shavelson, 1996), the term "concept" takes the encyclopaedia format of metaphor (Eco, 1984), as it represents the knowledge surrounding the data, information, knowledge, process or task codified rather than abstract ideas, becoming knowledge structures that codify objects and their relation to each other (Oliveira et al., 2018).

The aim of Product Lifecycle Management (PLM) is to connect all the steps of creation, development and commercialization of a product. To foster connectivity, implementation of the PLM paradigm must consider:

- The contact points among existing departments;

- The impact of the deliverables generated by a team on the work of other teams;

- The knowledge of the data and information systems serving and used by each department.

Classifications based on each one of the developmental steps might already exist within the organization. Each classification, however, might reflect the thought paradigm that is particular to the department it serves, with no overlap or contact point between classifications. In an organization that has not somehow adopted PLM principles, if connections among departments exist, happen in an informal way. They are not supported by information systems. They may poorly documented in policies or procedures or even not documented at all. However, if informal collaboration exists, it implies different manifestations of tacit knowledge, for example:

- Knowledge about the common points and areas among departments;

- Knowledge about the organizational culture;

- Personal contacts in other teams;

- Problem resolution capacity.

If informal collaboration exists, a certain knowledge of what is missing to create that connectivity already exists before the implementation of the product lifecycle management paradigm, be it documented or not. This knowledge resides mostly in employees and is lost when those employees leave the organization. On the other hand, the conversion of all this tacit knowledge into explicit knowledge is expensive, sometimes not possible and may not yield the intended results, as explicit knowledge requires the use of language and logic, which invariably leads to the reduction of the multifaceted nature of tacit knowledge.

It is however possible to represent tacit knowledge in a fashion that is clear enough for some uses without actually converting all of it into explicit knowledge. In this process, named tacit knowledge capture, the exteriorization level sought is lower than the one necessary for creation of discursive documents. Captured tacit knowledge is different from explicit knowledge as it keeps most of its multifaceted nature.

Whereas product lifecycles may be based on theoretical logic and leave the task of adapting ongoing practices to employees, using captured tacit knowledge has the advantage of adapting product lifecycle to the organization's reality, taking into account the ongoing practices and making it easier for employees to adopt changes.

As ongoing practices may be poorly documented or even not documented at all, they are a part of employees' tacit knowledge. Concept maps would be useful to identify those ongoing practices. Product lifecycle management involves the interaction among different departments. The interaction among employees of different departments is the best information source to promote the understanding and capture of the interplay of these practices.

The only technique exploring the interaction among participants is the focus groups, which is characterized by three elements: aim at data collection; have the interaction among participants as the 
data source and rely on the active role of a facilitator to motivate the group discussion to produce data (Morgan, 1996). The facilitator's mission is to instigate and guide the discussion without ever intervening too much, creating the space for participants to build their own "'hierarchy of importance', their language and concepts, their frameworks for understanding the world" (Kitzinger, 1994, p. 108) and represent their expertise domain (Hoffman \& Lintern, 2006). Finding the balance between the intervention and the silence requires a lot of training and preparation on the part of the facilitator, as much as a dose of tact and diplomacy. When facilitation goes well, the group discussion leads participants to express the reasoning behind their way of thinking (Kitzinger, 1994) and may also help participants to enumerate essential information those participants develop or use, which can be invaluable to identify the data sources actually used in each product lifecycle phase.

The collaborative creation of concept maps in a group discussion session, previously named "participatory diagramming" (Kesby, 2000) or "diagrammatic elicitation" (Umoquit et al., 2013), allows for the identification of common knowledge zones (Hughes \& DuMont, 2002) as well as unique ones, in addition to the identification of the context surrounding the use of a term in a specific department.

The collaborative creation of concept maps has the potential to clarify the knowledge representation and therefore facilitate the integration of multiple data and information sources, of workflows from the beginning to the end of life of a product and of the tacit knowledge involved.

The resulting concept map would represent the vision of the specialized staff on the product lifecycle. Concept maps have a potential that has yet to be fully explored in the development of ontologies designed to be implemented in product lifecycle management.

\section{BENEFITS OF THE COLLABORATIVE CREATION OF CONCEPT MAPS}

Collective creation of concept maps hosts the expression of the negotiation in a group. They allow for the group to weigh their conflicting interests and find solutions that reflect their core values. Prioritizing conflicting interests is a very difficult and possibly delicate exercise for the researcher on their own.

Concept maps are versatile. They can be reused as the starting point for ontologies, for controlled vocabularies or taxonomies, among others.

The collaborative creation of concept maps has the potential to reduce the number of hours employed in document analysis by the researchers to create the ontology to support the product lifecycle management system.

One of the main advantages of the collaborative creation of concept maps is that it allows the influence of specialized staff of the organization in the design process of the systems they are potential users. Integrating these employees in the conceptual creation of the product lifecycle management may reduce the framework resistance episodes as the framework itself will be better adapted to their needs and perspectives. This the staff that can generate the greatest resistance to product lifecycle management (Wognum \& Kerssens-Van Drongelen, 2005).

Finally, the collaborative creation of concept maps may increase employees' awareness of the impact of their work over other teams, especially where departments evolve in great isolation from others.

\section{COLLABORATIVE CREATION OF CONCEPT MAPS LIMITATIONS}

One of the consequences of the retention of the multifaceted nature of tacit knowledge is that the concept map might not carry enough richness to promote the analysis and understanding of researchers. Sessions designed to validate the ontology may be considered.

Tacit knowledge is also very context specific. A concept map may have limited generalization potential.

\section{CONCLUSION}

In this study, the creation of a concept map focused on the product lifecycle helped the participant navigate data and information from other teams using their own mental model, creating connexions between their informational environment and the one from other teams. The exercise of expressing the connexions between concepts gave the potential user the opportunity to exteriorize a lot of the tacit knowledge involving work with those concepts, providing a rich opportunity of mental model transfer to the design researcher. Concept maps are indeed useful tools in the capture of tacit knowledge.

The potential of specialized staffs' tacit knowledge may help the data analysis work that is necessary for the resolution of semantic heterogeneity was recognized. 
While the collective creation of concept maps does not replace other design research frameworks, such as DRM (Blessing \& Chakrabarti, 2009), it does provide a resource to better represent and transfer the meaning structures surrounding the user behaviour through their data, information and knowledge environment. The tool and methodology may also foster the identification or creation of connections between data, information and knowledge sources, facilitating the design of interfaces intended to represent knowledge.

\section{REFERENCES}

Ambrosini, V., \& Bowman, C. (2001). Tacit Knowledge: Some Suggestions for Operationalization. Journal of Management Studies, 38(6), 811-829. https://doi.org/10.1111/1467-6486.00260

Anand, G., Ward, P. T., \& Tatikonda, M. V. (2010). Role of explicit and tacit knowledge in Six Sigma projects: An empirical examination of differential project success. Journal of Operations Management, 28(4), 303-315. https://doi.org/10.1016/j.jom.2009.10.003

Arduin, P.-E., Duigou, J. L., Abel, M.-H., \& Eynard, B. (2018). Sharing Knowledge When it Cannot be Made Explicit: The Case of Product Lifecycle Management Systems. International Journal of Knowledge-Based Organizations (IJKBO), 8(4), 14-28. https://doi.org/10.4018/IJKBO.2018100102

Babish, N. (2019, October 21). How to Learn More About Your Users with a Contextual Inquiry. Shopify. https://www.shopify.ca/partners/blog/contextual-inquiry

Banks, Marcus. (2001). Visual methods in social research. SAGE.

Batenburg, R., Helms, R. W., \& Versendaal, J. (2006). PLM roadmap: Stepwise PLM implementation based on the concepts of maturity and alignment. International Journal of Product Lifecycle Management, 1(4), 333-351. https://doi.org/10.1504/IJPLM.2006.011053

Blessing, L. T. M., \& Chakrabarti, A. (Eds.). (2009). DRM: A Design Reseach Methodology. In DRM, a Design Research Methodology (pp. 13-42). Springer. https://doi.org/10.1007/978-1-84882-587-1_2

Brilhante, V., Macedo, G., \& Macedo, S. (2006). Heuristic transformation of well-constructed conceptual maps into owl preliminary domain ontologies. Workshop on Ontologies and Their Applications, WONTO.

Brown, J. S., \& Duguid, P. (2000). Balancing Act: How to Capture Knowledge Without Killing It. Harvard Business Review, 78(3), 73. Expanded Academic ASAP.

Castro, A. G., Rocca-Serra, P., Stevens, R., Taylor, C., Nashar, K., Ragan, M. A., \& Sansone, S.-A. (2006). The use of concept maps during knowledge elicitation in ontology development processes - the nutrigenomics use case. BMC Bioinformatics, 7, 267. https://doi.org/10.1186/1471-2105-7-267

Cowan, R., \& Foray, D. (1997). The Economics of Codification and the Diffusion of Knowledge. Industrial and Corporate Change, 6(3), 595-622. https://doi.org/10.1093/icc/6.3.595

Dalkir, K. (2017). Knowledge management in theory and practice (Third edition). The MIT Press.

Dixon, N. M. (1999). A theoretical framework of individual learning. In Organizational Learning Cycle: How We Can Learn Collectively (pp. 13-42). Gower Publishing Limited. http://site.ebrary.com/lib/alltitles/docDetail.action?docID=10050478

Eco, U. (1984). Metaphor, Dictionary, and Encyclopedia. New Literary History, 15(2), 255-271. https://doi.org/10.2307/468855

Garshol, L. M. (2004). Metadata? Thesauri? Taxonomies? Topic maps! Making sense of it all. Journal of Information Science, 30(4), 378-391. https://doi.org/10.1177/0165551504045856

Gruber, T. R. (1993). A translation approach to portable ontology specifications. Knowledge Acquisition, 5(2), 199-220.

Hall, A. V. (1994). Understanding the powerful grouping sense through a unifying classification theory. Knowledge Organization, 21(3), 126-131.

Hoffman, R. R., \& Lintern, G. (2006). Eliciting and representing the knowledge of experts. Cambridge Handbook of Expertise and Expert Performance, 203-222.

Hughes, D. L., \& DuMont, K. (2002). Using focus groups to facilitate culturally anchored research. In Ecological research to promote social change (pp. 257-289). Springer.

Joseph, M. F., \& Lourdusamy, R. (2018). Ontology mediation method for building multilingual ontologies. International Journal of Information Technology, 10(1), 11-19. https://doi.org/10.1007/s41870-017-0068-x

Kadiri, S. E., \& Kiritsis, D. (2015). Ontologies in the context of product lifecycle management: State of the art literature review. International Journal of Production Research, 53(18), 5657-5668. https://doi.org/10.1080/00207543.2015.1052155

Kale, V. (2016). Enhancing enterprise intelligence: Leveraging ERP, CRM, SCM, PLM, BPM, and BI. CRC Press, Taylor \& Francis Group.

Kärkkäinen, H., Pels, H. J., \& Silventoinen, A. (2012). Defining the Customer Dimension of PLM Maturity. In L. Rivest, A. Bouras, \& B. Louhichi (Eds.), Product Lifecycle Management. Towards Knowledge-Rich Enterprises (pp. 623-634). Springer Berlin Heidelberg. 
Kermanshahani, S. (2009). IXIA (IndeX-based Integration Approach) A Hybrid Approach to Data Integration [Phd thesis]. Université Joseph-Fourier - Grenoble I.

Kesby, M. (2000). Participatory diagramming as a means to improve communication about sex in rural Zimbabwe: A pilot study. Social Science and Medicine, 50(12), 1723-1741. Scopus. https://doi.org/10.1016/S0277-9536(99)00413-X

Kitzinger, J. (1994). The methodology of Focus Groups: The importance of interaction between research participants. Sociology of Health \& Illness, 16(1), 103-121. Scopus. https://doi.org/10.1111/14679566.ep11347023

Lanzenberger, M., Sampson, J., Kargl, H., Wimmer, M., Conroy, C., O’Sullivan, D., Lewis, D., Brennan, R., Ramos-Gargantilla, J. Á., \& Gómez-Pérez, A. (2008). Making ontologies talk: Knowledge interoperability in the semantic web. IEEE Intelligent Systems, 23(6), 72-85.

Lim, E. H. Y., Liu, J. N. K., \& Lee, R. S. T. (2011). Collaborative Content and User-Based Web Ontology Learning System. In E. H. Y. Lim, J. N. K. Liu, \& R. S. T. Lee (Eds.), Knowledge Seeker-Ontology Modelling for Information Search and Management: A Compendium (pp. 181-194). Springer. https://doi.org/10.1007/978-3-642-17916-7_12

Morgan, D. L. (1996). Focus Groups. Annual Review of Sociology, 22, 129-152. JSTOR.

Nelson, R., Victor, D. G., \& Steil, R. R. (2002). Technological Innovation and Economic Performance. Princeton University Press.

Nielsen, L. (2019). Personas-User focused design (Second edition., Vol. 1-1 online resource (ix, 170 pages) : illustrations (some color)). Springer.

Nonaka, I., \& Konno, N. (1998). The Concept of "Ba": Building a Foundation for Knowledge Creation. California Management Review, 40(3), 40-54. https://doi.org/10.2307/41165942

Nonaka, I., \& Takeuchi, H. (1995). The knowledge-creating company. Oxford University Press.

Novak, J. D., \& Cañas, A. J. (2009). What is a Concept Map? Cmap. https://cmap.ihmc.us/docs/conceptmap.php

Oliveira, D., Gardoni, M., \& Dalkir, K. (2018). Environmental Factors on Concept Maps Design. In P. Chiabert, A. Bouras, F. Noël, \& J. Ríos (Eds.), Product Lifecycle Management to Support Industry 4.0 (pp. 25-34). Springer International Publishing. 10.1007/978-3-030-01614-2_3

Pellini, A., \& Jones, H. (2011). Knowledge taxonomies: A literature review.

Pincher, M. (2010). A guide to developing taxonomies for effective data management. Computer Weekly, 8.

Rambo, J., Schendel, C., \& Richter, M. (2007). The Use of Concept Mapping to Support Collaborative Advanced Design Projects. DS 42: Proceedings of ICED 2007, the 16th International Conference on Engineering Design, Paris, France, 28.-31.07.2007, 391-392 (exec. Summ.), full paper no. DS42_P_415.

Ruiz-Primo, M. A., \& Shavelson, R. J. (1996). Problems and issues in the use of concept maps in science assessment. Journal of Research in Science Teaching, 33(6), 569-600. https://doi.org/10.1002/(SICI)10982736(199608)33:6\%3c569::AID-TEA1\%3e3.0.CO;2-M

Sheth, A. (1999). Changing focus on interoperability in information systems: From system, syntax, structure to semantics. In Interoperating geographic information systems (pp. 5-29). Springer.

Sheth, A., \& Kashyap, V. (1993). So Far (Schematically) yet So Near (Semantically). In D. K. Hsiao, E. J. Neuhold, \& R. Sacks-davis (Eds.), Interoperable Database Systems (Ds-5) (pp. 283-312). North-Holland. https://doi.org/10.1016/B978-0-444-89879-1.50022-1

Smirnov, A., \& Shilov, N. (2018). Multi-aspect Ontology for Semantic Interoperability in PLM: Analysis of Possible Notations. In P. Chiabert, A. Bouras, F. Noël, \& J. Ríos (Eds.), Product Lifecycle Management to Support Industry 4.0 (pp. 314-323). Springer International Publishing.

Sowa, J. F. (1992). Conceptual graphs as a universal knowledge representation. Computers \& Mathematics with Applications, 23(2), 75-93. https://doi.org/10.1016/0898-1221(92)90137-7

Starr, R. R., \& Oliveira, J. M. P. de. (2013). Concept maps as the first step in an ontology construction method. Information Systems, 38(5), 771-783. https://doi.org/10.1016/j.is.2012.05.010

Stoyanova, N., \& Kommers, P. (2002). Concept mapping as a medium of shared cognition in computersupported collaborative problem solving. Journal of Interactive Learning Research, 13(1), 111.

Umoquit, M., Tso, P., Burchett, H. E., \& Dobrow, M. J. (2011). A multidisciplinary systematic review of the use of diagrams as a means of collecting data from research subjects: Application, benefits and recommendations. BMC Medical Research Methodology, 11(1), 11. https://doi.org/10.1186/1471-2288-11-11

Umoquit, M., Tso, P., Varga-Atkins, T., O’Brien, M., \& Wheeldon, J. (2013). Diagrammatic elicitation: Defining the use of diagrams in data collection. Qualitative Report, 18(30).

Wognum, P. M., \& Kerssens-van Drongelen, I. C. (2000). Process and impact of product data management implementation. IFAC Proceedings Volumes, 33(20), 549-551. https://doi.org/10.1016/S14746670(17)38108-9

Wognum, P. M., \& Kerssens-Van Drongelen, I. C. (2005). Process and impact of product data management implementation. International Journal of Product Development, 2(1-2), 5-23. https://doi.org/10.1504/IJPD.2005.006666

Yao, J., \& Gu, M. (2013). Conceptology: Using Concept Map for Knowledge Representation and Ontology Construction. Journal of Networks, 8(8), 1708-1712. 